\title{
Visual function after implantation of a diffractive aspheric trifocal intraocular lens
}

\author{
José F. Alfonso ${ }^{1,2}$, Luis Fernández-Vega Cueto ${ }^{1}$, Lurdes Belda-Salmerón ${ }^{3}$, Robert Montés-Micó ${ }^{3}$, Luis Fernández-Vega ${ }^{1,2}$ \\ ${ }^{1}$ Fernández-Vega Ophthalmological Institute, Oviedo - Spain \\ ${ }^{2}$ Surgery Department, School of Medicine, University of Oviedo, Oviedo - Spain \\ ${ }^{3} \mathrm{GIO}$, Optics and Optometry and Vision Sciences Department, Faculty of Physics, University of Valencia, Oviedo - Spain
}

\begin{abstract}
Purpose: To evaluate distance, intermediate, and near vision after bilateral implantation of a diffractive aspheric trifocal intraocular lens (IOL).

Methods: This study enrolled 204 eyes of 102 patients who had bilateral implantation of the AT LISA tri 839MP IOL. Monocular and binocular uncorrected distance visual acuity (UDVA) and corrected distance visual acuity (CDVA) (4 meters), monocular and binocular uncorrected near visual acuity (UNVA) and distance-corrected near visual acuity (DCNVA) (30, 40 centimeters), binocular uncorrected intermediate visual acuity (UIVA) and distancecorrected intermediate visual acuity (DCIVA) $(50,60,70$ centimeters), the defocus curve, and binocular photopic and mesopic contrast sensitivity with and without glare were evaluated over 6 months.

Results: No statistically significant differences in visual acuity outcomes between follow-up visits were found at any distance evaluated ( $p>0.05$ ). Six months postoperatively, the mean monocular UDVA and UNVA were comparable to preoperative CDVA and DCNVA, respectively. All patients achieved a binocular CDVA of 20/25 or better. The mean binocular DCIVA ranged from $0.11 \pm 0.11(70 \mathrm{~cm})$ to $0.07 \pm 0.11 \operatorname{logMAR}(50 \mathrm{~cm})$. The mean binocular DCNVA was $20 / 25$ or better in nearly $87 \%$ of patients. The defocus curve showed a wide range of useful vision, with no statistically significant differences in visual acuity at intermediate distances $(p=0.151)$. Mesopic contrast sensitivity was lower than under photopic conditions, particularly at medium and high spatial frequencies $(p<0.001)$.

Conclusions: Bilateral implantation of this trifocal IOL provides good visual outcomes at far, intermediate, and near distances, being an effective solution to reduce spectacle dependence after lensectomy.
\end{abstract}

Keywords: Contrast sensitivity, Intermediate vision, Trifocal intraocular lens, Visual acuity

\section{Introduction}

Multifocal intraocular lenses (IOLs) have been introduced into clinical practice as an optical solution to satisfy the visual demands of presbyopic patients who wish to be spectacle independent. In recent years, many studies have demonstrated that refractive (1-4), diffractive (5-9), and hybrid (10-14) IOLs provide good distance and near vision when implanted. However, the visual function at intermediate distance in patients with these bifocal IOLs has been shown to be somewhat poorer compared with that at far and near distances (15-18).

Accepted: December 18, 2015

Published online: January 18, 2016

Corresponding author:

José F. Alfonso, MD, PhD

Instituto Oftalmológico Fernández-Vega

Avda. Dres. Fernández-Vega 114

33012 Oviedo, Spain

j.alfonso@fernandez-vega.com
Besides far and near vision, the achievement of a functional intermediate vision after cataract surgery is also crucial for patients with presbyopia; for example, for tasks related to computer use. In this sense, new IOL designs providing 3 main foci-devoted to far, intermediate, and near vision-have been developed (19-21). The AT LISA tri 839MP IOL (Carl Zeiss Meditec, Jena, Germany) uses this trifocal design in the center of the IOL with a conventional bifocal diffractive pattern on the periphery. To date, there are few clinical studies assessing visual performance after implantation of this new trifocal IOL (22-25). A comparative study by Mojzis et al (22) showed significantly better intermediate vision provided by the AT LISA tri 839MP IOL over its bifocal predecessor with equivalent postoperative levels of visual and ocular optical quality. Mojzis et al (23) and Law et al (24) reported excellent distance, intermediate, and near visual outcomes with high levels of patient satisfaction through the first months following surgery. These results agree with those reported by Marques and Ferreira (25) in a recent study. However, all studies enrolled a small series of 15 to 30 patients in which the trifocal IOL was implanted. 
The aim of the present study was to assess distance, intermediate, and near visual acuities and distance contrast sensitivity under photopic and mesopic conditions in a larger sample of patients who had bilateral implantation of the AT LISA tri 839MP IOL after lensectomy.

\section{Methods}

This prospective study comprised patients who had lensectomy with the bilateral implantation of the AT LISA tri 839MP trifocal IOL at the Fernández-Vega Ophthalmological Institute, Oviedo, Spain. The research was performed in accordance with the tenets of the Declaration of Helsinki and was approved by an institutional review board. Informed consent was obtained from all patients after receiving a full explanation of the nature and possible consequences of the study.

Inclusion criteria were age between 43 and 75 years, bilateral IOL implantation, and the common desire to achieve spectacle or contact lens independence for any working distance. Exclusion criteria included corneal astigmatism of $1.50 \mathrm{D}$ or higher, history of glaucoma or retinal detachment, corneal disease, previous corneal or intraocular surgery, abnormal iris, pupil deformation, macular degeneration or retinopathy, neuro-ophthalmic disease, and history of ocular inflammation.

\section{Preoperative assessment}

Before surgery, all patients had a complete ophthalmologic examination including manifest refraction, keratometry, slit-lamp biomicroscopy, Goldmann applanation tonometry, and binocular indirect ophthalmoscopy through dilated pupils. Axial length and anterior segment size were measured with a noncontact optical biometer (IOLMaster; Carl Zeiss Meditec). Pupil diameter with distance vision was measured at 2 different levels of illumination using a pupillometer (Colvard; Oasis, San Dimas, CA).

\section{Intraocular lens}

The AT LISA tri 839MP is a single-piece aspheric diffractive multifocal IOL with a 6.0-mm biconvex optic, an overall diameter of $11.0 \mathrm{~mm}$, and 0 -degree haptic angulation. The optic design of the IOL combines a central trifocal zone of $4.34 \mathrm{~mm}$ diameter with a bifocal zone on the periphery from 4.34 to $6.0 \mathrm{~mm}$. In the central zone, the AT LISA tri 839MP IOL provides a near addition of $+3.33 \mathrm{D}$ and an intermediate addition of $+1.66 \mathrm{D}$ at the IOL plane. The incident light is distributed asymmetrically with $50 \%, 20 \%$, and $30 \%$ to distance, intermediate, and near foci, respectively. The IOL has an aspheric profile to correct positive spherical aberration of the cornea. The optic is made of foldable hydrophilic acrylate (refractive index 1.46) with $25 \%$ water content and hydrophobic surface properties. The hydrophobic surface of the lens has a 360-degree square edge to reduce posterior capsule opacification. The IOL power varies from 0.00 to $+32.00 \mathrm{D}$ in $0.50 \mathrm{D}$ steps.

\section{Surgical technique}

The same experienced surgeon (J.F.A.) performed all surgeries. The technique included topical anesthesia, a $2.2-\mathrm{mm}$ clear corneal microincision, capsulorhexis creation, and phacoemulsification (Infiniti Vision System; Alcon Laboratories, Fort Worth, TX). Phacoemulsification was followed by irrigation and aspiration of the cortex and implantation of the AT LISA tri 839MP trifocal IOL in the capsular bag using the Bluemixs 180 injector (Carl Zeiss Meditec). Postoperative topical therapy including anti-inflammatory and antibiotic medications was used for 4 weeks. The time between the 2 surgeries was 7 days.

\section{Postoperative assessment}

Postoperative follow-up visits were scheduled at 1 day, 1 week, and 1, 3, and 6 months. The standard ophthalmologic examinations included manifest refraction, visual performance, slit-lamp biomicroscopy, Goldmann applanation tonometry, and binocular indirect ophthalmoscopy through dilated pupils. Intraocular lens tilt and centration were assessed using a Scheimpflug videophotography system (EAS-1000; Nidek, Aichi, Japan).

Visual acuity (VA) measurements were performed under photopic conditions (85 candelas $[\mathrm{cd}] / \mathrm{m}^{2}$ ). Monocular and binocular uncorrected distance VA (UDVA) and corrected distance VA (CDVA) were measured at $100 \%$ contrast using Early Treatment of Diabetic Retinopathy Study (ETDRS) charts (Optec 6500; Stereo Optical Co., Chicago, IL) at 4 meters. Monocular and binocular uncorrected near VA (UNVA) and distance-corrected near VA (DCNVA) were measured using the Logarithmic Visual Acuity Chart 2000 New ETDRS (Precision Vision, Lasalle, IL) at 30 centimeters and 40 centimeters. Intermediate VA was assessed under binocular conditions. Binocular uncorrected intermediate VA (UIVA) and distancecorrected intermediate VA (DCIVA) were measured at 50 centimeters, 60 centimeters, and 70 centimeters with the same test used for near assessment but with an adjustment for distance. Through-focus binocular logMAR acuity (defocus curve) was measured 6 months after surgery to characterize the far, near, and intermediate visual function. Patients observed a distance logMAR chart through pairs of negative lenses increasing from +2.00 to $-5.00 \mathrm{D}$ in $0.50 \mathrm{D}$ steps.

Binocular photopic $\left(85 \mathrm{~cd} / \mathrm{m}^{2}\right)$ and mesopic $\left(3 \mathrm{~cd} / \mathrm{m}^{2}\right)$ contrast sensitivity with and without glare were measured with distance correction at spatial frequencies of $1.5,3,6,12$, and 18 cycles per degree using the functional acuity contrast test (Stereo Optical Co.) 6 months postoperatively. Before mesopic contrast sensitivity testing, patients remained 10 minutes inside the testing room under mesopic conditions in order to allow adaptation to the luminance conditions. Absolute $\log _{10}$ contrast sensitivity $\left(\log _{10} \mathrm{CS}\right)$ values were obtained for each combination of patient, spatial frequency, and luminance, and the mean values and standard deviations were calculated. All examinations were performed by the same ophthalmic technician, who was unaware of the objective of the study.

\section{Statistical analysis}

Data analysis was performed using SigmaPlot v12 software (Systat Software, San Jose, CA, USA). Normality was checked by the Shapiro-Wilk test. Statistical differences in visual outcomes between preoperative and 6 months postoperative were analyzed with the nonparametric Mann-Whitney $U$ test. 
TABLE I - Patient demographics

\begin{tabular}{lcc}
\hline & Mean \pm SD & Min, Max \\
\hline Age, $y$ & $60.5 \pm 8.5$ & 43,75 \\
Preoperative sphere, D & $-0.24 \pm 4.01$ & $-14.00,+7.50$ \\
Preoperative cylinder, D & $-0.70 \pm 0.32$ & $-1.50,0.00$ \\
Postoperative sphere, D & $-0.06 \pm 0.21$ & $-1.25,+1.00$ \\
Postoperative cylinder, D & $-0.09 \pm 0.21$ & $-0.75,0.00$ \\
Pupil diameter, mm & & \\
$\quad$ Photopic, $85 \mathrm{~cd} / \mathrm{m}^{2}$ & $3.9 \pm 0.9$ & $2.0,6.0$ \\
$\quad$ Mesopic, $3 \mathrm{~cd} / \mathrm{m}^{2}$ & $5.7 \pm 0.9$ & $3.0,7.0$ \\
AL, mm & $23.83 \pm 1.75$ & $20.66,28.78$ \\
IOL power, D & $19.48 \pm 5.35$ & $8.00,28.50$ \\
\hline
\end{tabular}

$\mathrm{AL}=$ axial length; $\mathrm{IOL}=$ intraocular lens.

The Friedman repeated measures analysis of variance on ranks test was used to evaluate differences in VA between followup visits and in contrast sensitivity under different luminance conditions. The multiple comparison post hoc Tukey test was performed when differences were found. The Kruskal-Wallis test was used to evaluate differences in VA in the intermediate distance range. Data are reported as mean \pm SD. Differences were considered statistically significant when the $p$ value was less than 0.05 .

\section{Results}

The study evaluated a total of 204 eyes of 102 patients ( 67 women, 35 men). The mean age was $60.5 \pm 8.5$ years (range 43-75 years). Table I shows patient demographics. There were no intraoperative complications in any case. After the surgery and multifocal IOL implantation, all patients had round pupils with no iris trauma and showed good responsiveness to light. All IOLs were well-centered and were not tilted.

\section{Visual acuity}

Figure 1 shows the mean monocular VA for far and near vision $(40 \mathrm{~cm})$ preoperatively and 6 months after multifocal IOL implantation. Regarding far vision, the mean postoperative monocular UDVA was comparable to preoperative monocular CDVA. When the postoperative residual refractive error was corrected (Tab. I), the mean monocular UDVA improved from $0.11 \pm 0.16 \log$ MAR (approximately 20/25) to $0.05 \pm$ $0.10 \log M A R(>20 / 25)$. At 6 months, the mean monocular CDVA was statistically significantly better than preoperatively $(p=0.002)$. Regarding near vision, the mean postoperative monocular UNVA was $0.17 \pm 0.13 \log$ MAR (about 20/32), which improved slightly to $0.14 \pm 0.12 \log$ MAR (approximately 20/25) with best distance correction. The mean postoperative monocular DCNVA was somewhat better than preoperatively; no statistical significance was found with respect to preoperative data $(p=0.835)$.

Table II summarizes the mean binocular distance, intermediate, and near visual acuities and the percentage of eyes

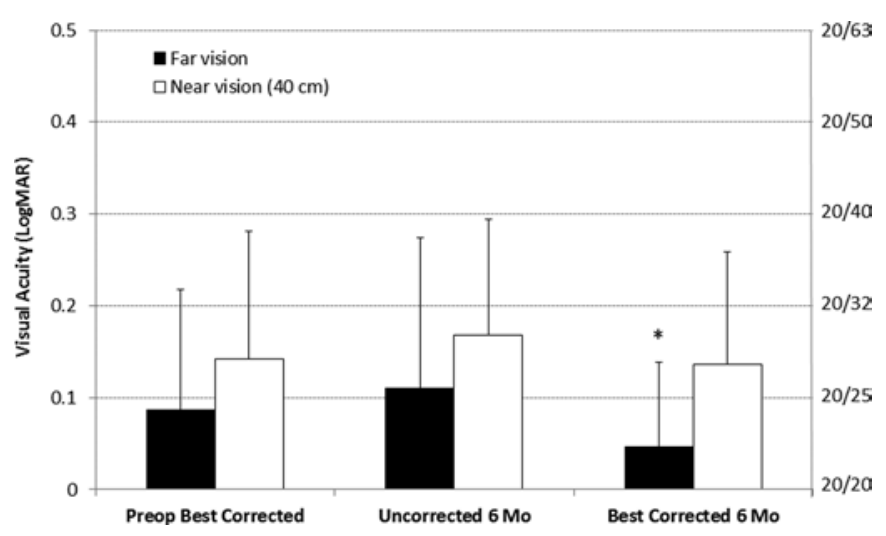

Fig. 1 - Bar graph shows monocular visual acuity (logMAR units) for far and near $(40 \mathrm{~cm})$ vision preoperatively and 6 months after the AT LISA tri 839MP intraocular lens implantation. The $y$-axis on the right shows the Snellen feet equivalent of the logMAR acuity. Error bars represent the standard deviation. *Statistically significant differences between preoperative and postoperative acuities.

having $20 / 40$ or better acuity and $20 / 25$ or better acuity at each distance over the 6-month follow-up. No statistically significant differences in VA (uncorrected and corrected) outcomes between follow-up visits were found at any distance evaluated $(p>0.05)$. Six months after multifocal IOL implantation, all patients achieved a binocular CDVA of 20/25 or better. The mean binocular UIVA and DCIVA ranged from $0.12 \pm 0.11$ and $0.11 \pm 0.11 \log$ MAR (approximately 20/25) at $70 \mathrm{~cm}$ to $0.08 \pm 0.11$ and $0.07 \pm 0.11 \log M A R(>20 / 25)$ at $50 \mathrm{~cm}$, respectively. The fewest patients achieved an acuity of 20/25 or better (uncorrected and corrected) at $60 \mathrm{~cm}$ distance. The mean binocular CNVA was $0.31 \pm 0.12 \log$ MAR (about 20/40) at $30 \mathrm{~cm}$ and $0.06 \pm 0.10 \log$ MAR (>20/25) when measured at $40 \mathrm{~cm}$, with approximately $87 \%$ of patients achieving $20 / 25$ or better acuity.

\section{Defocus curve}

Figure 2 shows the through-focus best corrected binocular logMAR VA at 6 months. As can be seen, the maximum value of VA was obtained at a vergence of $0.00 \mathrm{D}$, corresponding to the far focus. A second peak was found at approximately $-2.00 \mathrm{D}$ to $-2.50 \mathrm{D}$ defocus, corresponding to the near focus. Between these main foci, the curve showed a wide range of useful vision with VA values of $0.2 \log M A R$ or better, corresponding to the intermediate focus. No statistically significant differences in VA outcomes in the range between -2.00 and $-1.00 \mathrm{D}$ (equivalent to $50 \mathrm{~cm}$ and $1 \mathrm{~m}$, respectively) were found $(p=0.151)$.

\section{Contrast sensitivity under bright and dim conditions}

Figure 3 shows the mean binocular $\log _{10}$ CS values under photopic $\left(85 \mathrm{~cd} / \mathrm{m}^{2}\right)$ and mesopic $\left(3 \mathrm{~cd} / \mathrm{m}^{2}\right)$ conditions with and without glare 6 months postoperatively. The values are plotted as a series of contrast sensitivity functions at these 2 illumination levels. Contrast sensitivity under mesopic conditions with and without glare was lower than under photopic 
TABLE II - Binocular distance, intermediate, and near visual acuities (logMAR) after multifocal intraocular lens implantation

\begin{tabular}{|c|c|c|c|c|c|c|c|c|c|c|}
\hline \multirow[t]{2}{*}{ Test } & \multicolumn{3}{|c|}{1 Month } & \multicolumn{3}{|c|}{3 Months } & \multicolumn{3}{|c|}{6 Months } & \multirow{2}{*}{$\begin{array}{c}p \\
\text { Value }\end{array}$} \\
\hline & $\begin{array}{c}\text { Mean } \pm \\
\text { SD }\end{array}$ & $\begin{array}{c}\text { VA } 20 / 40 \\
\text { or better, } \\
n(\%)\end{array}$ & $\begin{array}{c}\text { VA } 20 / 25 \\
\text { or better, } \\
\text { n (\%) }\end{array}$ & $\begin{array}{c}\text { Mean } \pm \\
\text { SD }\end{array}$ & $\begin{array}{c}\text { VA } 20 / 40 \\
\text { or better, } \\
n(\%)\end{array}$ & $\begin{array}{c}\text { VA } 20 / 25 \\
\text { or better, } \\
n(\%)\end{array}$ & $\begin{array}{c}\text { Mean } \pm \\
\text { SD }\end{array}$ & $\begin{array}{c}\text { VA } 20 / 40 \\
\text { or better, } \\
n(\%)\end{array}$ & $\begin{array}{c}\text { VA } 20 / 25 \\
\text { or better, } \\
n(\%)\end{array}$ & \\
\hline \multicolumn{11}{|l|}{ Distance (4 m) } \\
\hline Uncorrected & $0.03 \pm 0.08$ & $101(100)$ & $87(86.1)$ & $0.02 \pm 0.07$ & $101(100)$ & $91(90.1)$ & & $101(100)$ & 94 (93.1) & 0.276 \\
\hline Best-corrected & $-0.02 \pm 0.06$ & $101(100)$ & $101(100)$ & $-0.02 \pm 0.05$ & $101(100)$ & $101(100)$ & & $101(100)$ & $101(100)$ & 0.368 \\
\hline Uncorrected & $0.12 \pm 0.09$ & $96(95.2)$ & 42 (41.6) & $0.12 \pm 0.10$ & $96(95.2)$ & $43(42.6)$ & $0.12 \pm 0.11$ & $96(95.2)$ & 48 (47.5) & 0.223 \\
\hline Best distance-corrected & $0.10 \pm 0.08$ & $96(95.2)$ & $48(47.5)$ & $0.11 \pm 0.10$ & $96(95.2)$ & $48(47.5)$ & $0.11 \pm 0.11$ & $96(95.2)$ & $58(57.4)$ & 0.449 \\
\hline \multicolumn{11}{|l|}{ Intermediate $(60 \mathrm{~cm})$} \\
\hline Uncorrected & $0.11 \pm 0.11$ & $91(90.1)$ & $29(28.7)$ & $0.12 \pm 0.10$ & 91 (90.1) & $29(28.7)$ & $0.13 \pm 0.10$ & $91(90.1)$ & $25(24.7)$ & 0.078 \\
\hline Best distance-corrected & $0.10 \pm 0.09$ & $96(95.0)$ & 38 (37.6) & $0.08 \pm 0.08$ & $101(100)$ & $38(37.6)$ & $0.09 \pm 0.08$ & $101(100)$ & 40 (39.6) & 0.497 \\
\hline \multicolumn{11}{|l|}{ Near $(40 \mathrm{~cm})$} \\
\hline Uncorrected & $0.10 \pm 0.10$ & $101(100)$ & $72(71.3)$ & $0.08 \pm 0.11$ & $101(100)$ & $82(81.2)$ & $0.07 \pm 0.11$ & $101(100)$ & $86(85.1)$ & 0.191 \\
\hline Best distance-corrected & $0.08 \pm 0.11$ & $101(100)$ & $82(81.2)$ & $0.07 \pm 0.11$ & $101(100)$ & 87 (86.1) & $0.06 \pm 0.10$ & $101(100)$ & $87(86.1)$ & 0.307 \\
\hline \multicolumn{11}{|l|}{ Near (30 cm) } \\
\hline Uncorrected & $0.32 \pm 0.11$ & $39(38.6)$ & 0 & $0.32 \pm 0.13$ & 39 (38.6) & 0 & $0.33 \pm 0.14$ & 39 (38.6) & 0 & 0.303 \\
\hline Best distance-corrected & $0.30 \pm 0.10$ & $43(42.5)$ & $1(1.0)$ & $0.31 \pm 0.11$ & $43(42.5)$ & $2(2.0)$ & $0.31 \pm 0.12$ & $43(42.5)$ & $2(2.0)$ & 0.462 \\
\hline
\end{tabular}

VA = visual acuity.

a Follow-up visits comparison (Friedman test).

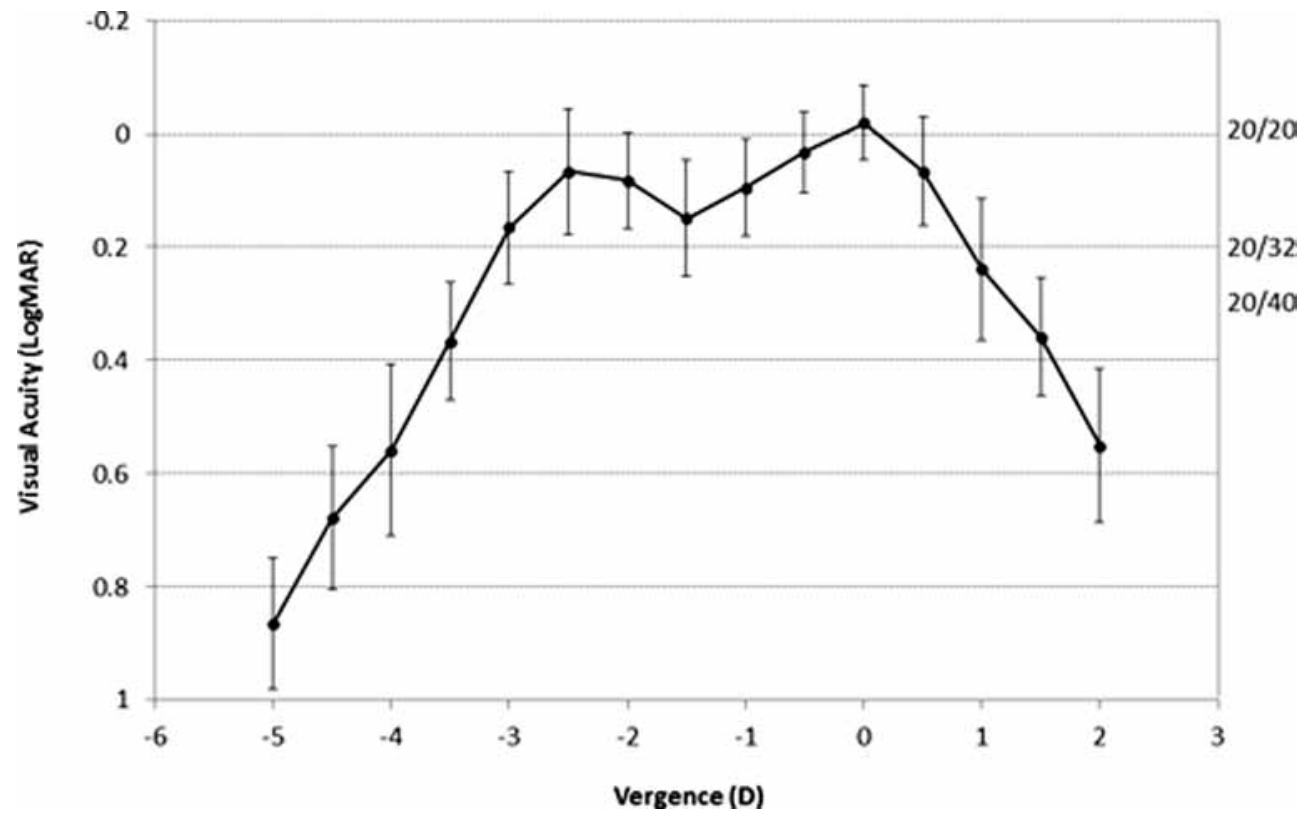

Fig. 2 - Mean high-contrast binocular visual acuity (logMAR) with best correction for distance vision as a function of the chart vergence for the AT LISA tri 839MP multifocal intraocular lens. The $y$-axis on the right shows the Snellen feet equivalent of the logMAR acuity. Error bars represent the standard deviation.

conditions at all spatial frequencies analyzed. Differences between the 2 lighting conditions were statistically significant at medium and high spatial frequencies $(p<0.001)$. There were no significant differences between contrast sensitivity under mesopic conditions with and without glare ( $p>0.05)$.

\section{Discussion}

Multifocal IOLs using a trifocal design have been developed recently with the intention of improving intermediate vision related to many daily activities (e.g., the use 

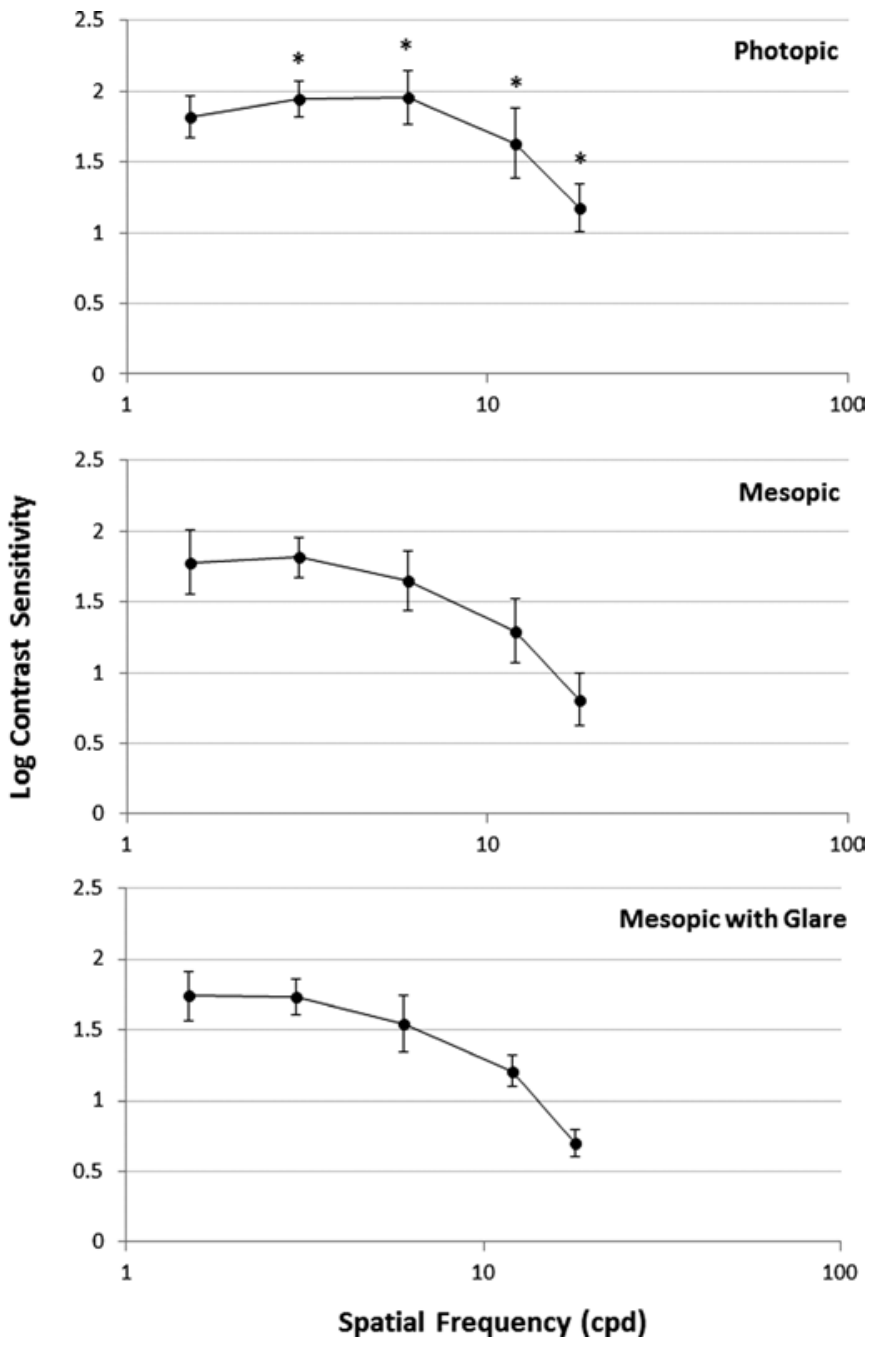

Fig. 3 - Graphs show binocular distance contrast sensitivity under photopic $\left(85 \mathrm{~cd} / \mathrm{m}^{2}\right)$ and mesopic $\left(3 \mathrm{~cd} / \mathrm{m}^{2}\right)$ conditions with and without glare 6 months after the AT LISA tri 839MP intraocular lens implantation. Error bars represents the standard deviation. Asterisks indicate statistically significant differences between the 2 luminance levels $(p<0.001)$. $c p d=$ cycles per degree.

of computers). The AT LISA tri 839MP IOL is based on this concept, combining a central trifocal zone that provides an addition of +3.33 $\mathrm{D}$ and +1.66 $\mathrm{D}$ for near and intermediate distances, respectively, with a bifocal diffractive pattern on the periphery. Previous clinical studies have reported the initial outcomes after implantation of this new trifocal IOL (22-25). However, all studies were focused on the short-term visual outcomes obtained in a small sample of patients after 3 to 6 months. The aim of the present study was to confirm the good results in terms of VA for different distances and contrast sensitivity provided by the AT LISA tri 839MP IOL in a larger sample of patients (204 eyes of 102 patients). To our knowledge, this represents the largest cohort evaluated after bilateral implantation of this trifocal IOL following lensectomy.

We found stable VA outcomes, with no statistically significant differences between follow-up visits. Six months post- operatively, the mean monocular UDVA and CDVA were 0.11 \pm 0.16 and $0.05 \pm 0.10 \log M A R$, respectively, with $100 \%$ of patients achieving a binocular CDVA of 20/25 or better. These results are similar to those recently reported by Marques and Ferreira (25) $(0.08 \pm 0.12$ and $0.04 \pm 0.10 \operatorname{logMAR}$, respectively), who also found a postoperative CDVA of 0.1 logMAR or better (20/25) in all eyes (30 eyes) at 3 months. However, both our monocular UDVA and CDVA are slightly lower than those found by Mojzis et al (23) (-0.03 \pm 0.09 and $-0.05 \pm 0.08 \log M A R$, respectively) and Law et al (24) $(0.05$ \pm 0.07 and $-0.02 \pm 0.05 \log M A R$, respectively) in a sample of 30 patients (60 eyes) 6 months after bilateral implantation of the AT LISA tri 839MP IOL. Regarding near vision, we obtained monocular UNVA (0.17 $\pm 0.13 \log$ MAR) and DCNVA $(0.14 \pm 0.12 \log M A R)$ results at the last follow-up visit of the same magnitude or better than those reported in previous studies with the same trifocal IOL (22-25). Furthermore, our study found good outcomes of postoperative binocular UNVA (0.07 $\pm 0.11 \log M A R)$ and DCNVA (0.06 \pm 0.10 logMAR), with $87 \%$ of patients achieving $0.1 \log$ MAR or better DCNVA (20/25) at $40 \mathrm{~cm}$, which are considered suitable to obtain a high level of spectacle independence. Note that although all studies evaluated the same IOL model, differences in factors such as sample size, patient characteristics, postoperative follow-up period, and VA testing may explain this difference in VA outcomes between the studies.

In the present study, both corrected and uncorrected VA for far and near vision were comparable to those previously reported after implantation of earlier bifocal IOLs $(18,26$, $27)$. This is consistent with findings in a recent comparative study by Mojzis et al (22). They found that VA results for far and near vision were similar and significantly better with the AT LISA tri 839MP IOL, respectively, compared to those with its bifocal predecessor (AT LISA 801, Carl Zeiss Meditec). These results suggest, therefore, that the creation of a third intermediate focus does not involve a detriment in of the other 2 main foci, the far focus and the near focus.

Our study had good VA results for intermediate distance. Six months postoperatively, the mean binocular DCIVA was $0.07 \pm 0.11$ (>20/25), $0.09 \pm 0.08$ (>20/25), and $0.11 \pm 0.11 \log$ MAR (approximately $20 / 25$ ) at $50 \mathrm{~cm}, 60 \mathrm{~cm}$, and $70 \mathrm{~cm}$, respectively. These results agree with those reported in previous studies assessing the same IOL (22-25). Marques and Ferreira (25) reported $0.13 \pm 0.42$ and $0.09 \pm$ $0.04 \log$ MAR UIVA and DCIVA $(80 \mathrm{~cm})$, respectively, at 3-month follow-up. Law et al (24) found in a sample of 30 patients who had bilateral implantation of this trifocal IOL a 3-month postoperative binocular DCIVA $(70 \mathrm{~cm})$ of $0.16 \pm$ $0.07 \operatorname{logRAD}$. In a recent study, Mojzis et al (23) reported a monocular logMAR UIVA and CDIVA $(66 \mathrm{~cm})$ of $0.08 \pm$ 0.10 and $0.08 \pm 0.10$, respectively, 6 months after IOL implantation. Moreover, they reported better visual outcomes at intermediate distances $(66$ and $80 \mathrm{~cm}$ ) with the AT LISA tri $839 \mathrm{MP}$ IOL when compared with those provided by its bifocal predecessor (22). Similarly as for far and near vision, differences in intermediate VA between the studies may be attributed to differences in sample size, patient characteristics, follow-up period, and distances used for VA testing. 
As expected, the introduction of an intermediate focus in the optic design of the IOL resulted in an improvement in intermediate vision over the earlier bifocal IOL models, without compromising distance or near performance. In this sense, the defocus curve showed 2 excellent peaks corresponding to the distance focus (0.00 D defocus) and the near focus (-2.00 D to $-2.50 \mathrm{D}$ defocus). The sharp drop in VA commonly obtained in the intermediate distance range with bifocal IOLs was not observed here, but there was a wide range of useful vision between distance and near foci. This finding is in accordance with the defocus curve reported by previous studies from a smaller sample of patients who had implantation of the same trifocal IOL (22-25).

Regarding contrast sensitivity, the 6-month postoperative mean values obtained under photopic conditions were consistent with those reported in previous series $(22,23)$, and slightly higher than those recently reported by Marques and Ferreira (25). Our study found a reduction of the mesopic contrast sensitivity values both with and without glare in relation to photopic conditions, with statistical significance at medium and high spatial frequencies. This trend agrees with contrast sensitivity changes previously reported in patients with bifocal IOLs $(3,4)$. It should be taken into account that the optic design of the AT LISA tri 839MP IOL combines a central trifocal zone of $4.34-\mathrm{mm}$ diameter with a bifocal zone on the periphery. Therefore, when luminance level is reduced, a larger pupil diameter is reached (Tab. I) and consequently, a higher weight of the effect of IOL peripheral zone may be observed. A recent study by Law et al (24) with the same IOL also showed lower values of monocular mesopic contrast sensitivity in relation to photopic conditions both measured with the Pelli-Robson chart, although the difference in this parameter did not reach statistical significance $(p>0.05)$.

Multifocal IOLs are associated with photic phenomena (i.e., halos, glare, and positive dysphotopsia) as a result of creating multiple images with simultaneous focuses (17, 28). Because the design of the AT LISA tri 839MP IOL has fewer rings on the surface compared to earlier multifocal IOLs (e.g., the AT LISA IOL has 28) and no sharp angles in the optical surface, less photic phenomena are expected. In the present study, patients were satisfied with the visual outcomes achieved, especially in performing intermediate distance tasks. No patients complained of disturbing phenomena after the surgical procedure. Our findings are in line with the low photic phenomena scores reported in the recent study by Marques and Ferreira (25) after implantation of this trifocal IOL.

In summary, the present study found that bilateral implantation of the AT LISA tri 839MP IOL provided stable and good high-contrast VA outcomes at distance and near, with a satisfactory range of intermediate vision. Distance contrast sensitivity was better under photopic conditions and comparable with mesopic lighting conditions at low spatial frequencies. These good visual quality outcomes support the implantation of this trifocal IOL as an effective solution to reduce spectacle dependence after lensectomy, enabling patients to feel more comfortable in daily activities. Future studies should include a longer follow-up to assess the safety and stability of this surgical procedure.

\section{Disclosures}

Financial support: Supported in part by a Ministerio de Educación, Cultura y Deporte Research Scholarship to Lurdes Belda-Salmerón (FPU\#AP2010-2107\#).

Conflict of interest: None of the authors has conflict of interest with this submission.

\section{References}

1. Leyland M, Pringle E. Multifocal versus monofocal intraocular lenses after cataract extraction. Cochrane Database Syst Rev. 2006;(4):CD003169.

2. Packer $M$, Fine IH, Hoffman RS. Refractive lens exchange with the array multifocal intraocular lens. J Cataract Refract Surg. 2002;28(3):421-424.

3. Montés-Micó R, Alió JL. Distance and near contrast sensitivity function after multifocal intraocular lens implantation. J Cataract Refract Surg. 2003;29(4):703-711.

4. Montés-Micó R, España E, Bueno I, Charman WN, Menezo JL. Visual performance with multifocal intraocular lenses: mesopic contrast sensitivity under distance and near conditions. Ophthalmology. 2004;111(1):85-96.

5. Lindstrom RL. Food and Drug Administration study update. One-year results from 671 patients with the $3 \mathrm{M}$ multifocal intraocular lens. Ophthalmology. 1993;100(1):91-97.

6. Walkow T, Liekfeld A, Anders N, Pham DT, Hartmann C, Wollensak J. A prospective evaluation of a diffractive versus a refractive designed multifocal intraocular lens. Ophthalmology. 1997;104(9):1380-1386.

7. Schmidinger G, Simader C, Dejaco-Ruhswurm I, Skorpik C, Pieh S. Contrast sensitivity function in eyes with diffractive bifocal intraocular lenses. J Cataract Refract Surg. 2005;31(11): 2076-2083.

8. Alfonso JF, Fernández-Vega L, Señaris A, Montés-Micó R. Quality of vision with the Acri. Twin asymmetric diffractive bifocal intraocular lens system. J Cataract Refract Surg. 2007;33(2):197-202.

9. Fernández-Vega L, Alfonso JF, Baamonde MB, Montés-Micó R. Symmetric bilateral implantation of a distance-dominant diffractive bifocal intraocular lens. J Cataract Refract Surg. 2007;33(11):1913-1917.

10. Kohnen $T$, Allen D, Boureau $C$, et al. European multicenter study of the AcrySof ReSTOR apodized diffractive intraocular lens. Ophthalmology. 2006;113:584 e581.

11. Alfonso JF, Fernández-Vega L, Baamonde MB, Montés-Micó R. Prospective visual evaluation of apodized diffractive intraocular lenses. J Cataract Refract Surg. 2007;33(7):1235-1243.

12. Fernández-Vega L, Alfonso JF, Montés-Micó R, Amhaz H. Visual acuity tolerance to residual refractive errors in patients with an apodized diffractive intraocular lens. J Cataract Refract Surg. 2008;34(2):199-204.

13. Alfonso JF, Fernández-Vega $L$, Valcárcel $B$, Ferrer-Blasco $T$, Montés-Micó R. Outcomes and patient satisfaction after presbyopic bilateral lens exchange with the ResTOR IOL in emmetropic patients. J Refract Surg. 2010;26(12):927-933.

14. Blaylock JF, Si Z, Vickers C. Visual and refractive status at different focal distances after implantation of the ReSTOR multifocal intraocular lens. J Cataract Refract Surg. 2006;32(9): 1464-1473.

15. Alfonso JF, Fernández-Vega L, Blázquez JI, Montés-Micó R. Visual function comparison of 2 aspheric multifocal intraocular lenses. J Cataract Refract Surg. 2012;38(2):242-248.

16. Alió JL, Plaza-Puche AB, Piñero DP, Amparo F, Rodríguez-Prats $\mathrm{JL}$, Ayala MJ. Quality of life evaluation after implantation of 2 multifocal intraocular lens models and a monofocal model. J Cataract Refract Surg. 2011;37(4):638-648. 
17. Javitt JC, Steinert RF. Cataract extraction with multifocal intraocular lens implantation: a multinational clinical trial evaluating clinical, functional, and quality-of-life outcomes. Ophthalmology. 2000;107(11):2040-2048.

18. Alfonso JF, Fernández-Vega L, Puchades C, Montés-Micó R. Intermediate visual function with different multifocal intraocular lens models. J Cataract Refract Surg. 2010;36(5):733-739.

19. Gatinel D, Pagnoulle C, Houbrechts Y, Gobin L. Design and qualification of a diffractive trifocal optical profile for intraocular lenses. J Cataract Refract Surg. 2011;37(11):2060-2067.

20. Ruiz-Alcocer J, Madrid-Costa D, García-Lázaro S, Ferrer-Blasco T, Montés-Micó R. Optical performance of two new trifocal intraocular lenses: through-focus modulation transfer function and influence of pupil size. Clin Experiment Ophthalmol. 2014;42(3):271-276.

21. Voskresenskaya A, Pozdeyeva N, Pashtaev N, Batkov Y, Treushnicov V, Cherednik V. Initial results of trifocal diffractive IOL implantation. Graefes Arch Clin Exp Ophthalmol. 2010;248(9):1299-1306.

22. Mojzis P, Kukuckova L, Majerova K, Liehneova K, Piñero DP. Comparative analysis of the visual performance after cataract surgery with implantation of a bifocal or trifocal diffractive IOL. J Refract Surg. 2014;30(10):666-672.

23. Mojzis P, Peña-García P, Liehneova I, Ziak P, Alió JL. Outcomes of a new diffractive trifocal intraocular lens. J Cataract Refract Surg. 2014;40(1):60-69.

24. Law EM, Aggarwal RK, Kasaby H. Clinical outcomes with a new trifocal intraocular lens. Eur J Ophthalmol. 2014;24(4):501-508.

25. Marques EF, Ferreira TB. Comparison of visual outcomes of 2 diffractive trifocal intraocular lenses. J Cataract Refract Surg. 2015;41(2):354-363.

26. Alfonso JF, Fernández-Vega L, Amhaz H, Montés-Micó R, Valcárcel B, Ferrer-Blasco T. Visual function after implantation of an aspheric bifocal intraocular lens. J Cataract Refract Surg. 2009;35(5):885-892.

27. Fernandez-Vega L, Madrid-Costa D, Alfonso JF, Poo-Lopez A, Montes-Micò R. Bilateral implantation of the Acri.LISA bifocal intraocular lens in myopic eyes. Eur J Ophthalmol. 2010; 20(1):83-89.

28. de Vries NE, Nuijts RM. Multifocal intraocular lenses in cataract surgery: literature review of benefits and side effects. J Cataract Refract Surg. 2013;39(2):268-278. 